\title{
Visualisation of Perception of Experiential Activities in Business and Administration and Economy
}

\author{
Rosaura Fernández-Pascual \\ University of Granada, Spain \\ Ana Marín Jiménez \\ University of Granada, Spain \\ María Pilar Fernández- Sánchez \\ University of Granada, Spain
}

\begin{abstract}
This paper explores how to incorporate information visualization tools into qualitative studies to represent the underlying structure of knowledge. Information visualization plays a key role in many areas such as decision-making, data mining, market studies, or knowledge management. A case of experiential learning was developed for Quantitative Techniques in Business and Administration and Economy Degrees at the University of Granada, Spain. The goal is to analyze the opinion of students ( $n=227$ ) on the development of the activity through information visualization techniques. The gathered information was subjected to a categorization process to unify and homogenize the responses. After a term-clumping process, a co-word analysis using the VosViewer software is used to analyze the relationships among terms and provide the network maps. Results display the main associations and clusters of terms used when assessing the experiential activity, using qualitative techniques. In conclusion, the strengths of data visualization enabling a better understanding of data for qualitative studies are established.
\end{abstract}

Keywords: information visualization, term-based method, experiential learning, knowledge, quantitative techniques.

JEL classification: O30, A22, C88, Y91

Paper type: Research article

Received: Mar 04. 2021

Accepted: May 27, 2021

DOI: 10.54820/MUHF5293 


\section{Introduction}

Visual information processing plays a key role in many areas such as decisionmaking, communication, data mining, financial data analysis, stock market prices, or manufacturing quality control. There is an important body of literature and most parts of the papers are quantitative ones. The novelty of this research is that is focused on how to incorporate information visualization techniques (Stopar et al., 2019) effectively into qualitative studies, to represent the underlying structure of knowledge.

Varian (2009), defined information visualization as "the ability to take data-to be able to understand it, to process it, to extract value from it, to visualize it, and to communicate it." Recently, Sharma (2020) considers that "Analytics is the science of examining raw data with the purpose of drawing conclusions about that information and using it for decision-making" and examines the use of visualisation tools with different data measures.

According to the Institute of Development Studies (2013), data visualisation can be applied "to explain and to explore data" or "be used as a tool for analysis, finding patterns as well as discovering questions among other things." In line with Kirk (2016), we believe in the effectiveness of the representation and presentation of data to facilitate understanding.

Usually, the process of creating information visualization generally starts identifying the necessary information (Chen, 2017, pp. 7): "Information visualization is a cognitive process that is used for analysis and presentation, allowing us to better understand data and offering the opportunity to act upon the understanding it offers. It also enables effective communications and presentations, further solidifying the fact that the purpose of visualization is to gain insights".

This paper explores how to incorporate effectively information visualization tools, such as item density and network maps, using the VosViewer software designed to visualize scientific landscapes. The aim is to show the opinions gathered through a survey of open questions, on an experiential activity carried out for Quantitative Techniques in Business and Administration and Economy Degrees at the University of Granada, Spain.

We analyze the opinion stated by students on the development of an experiential activity (McCarthy, 2016; Kolb et al., 2017). Experiential learning in Business is an issue widely developed in the literature. Clark et al. (2010) note that "a quality entrepreneurship education program must include an experiential learning component" and the Association to Advance Collegiate Schools of Business (AACSB, 2020) suggest the use of experiential learning activities, inside and outside the classroom, as a strategy to "encourage, and promote both curricular and cocurricular activities and best practices through which business schools can have a positive societal impact". Experiential education "requires students to engage in a concrete experience (Do), reflect on that experience and other information (Reflect), develop theories based on experiences and knowledge (Think), and formulate a conclusion or solve a problem (Apply)." (Butler et al., 2019, pp. 12). In Business education, experiential learning approaches have focused on simulations of real-world business practices (Vohra, 2015). As Baden et al. (2013) indicate, the world is changing and teaching must think effectively about the education of future business leaders and consider this way of teaching in all kinds of subjects.

From a quantitative point of view, Coker et al. (2017), analyze student motivations and perceptions across and within five forms of experiential learning: study abroad, research, internships, service-learning, and leadership experiences. Haug et al., (2019), consider a multidimensional construct as a tool for active learning to study 
the Undergraduate business students' perceptions about engagement. Cañabate et al., (2020) in the field of collaborative learning, develop a cross-disciplinary dimensional analysis considering students' motivation, academic performance, students' relationships within cooperative groups, group organization, and teacher involvement, taking students from seven disciplines. Sureka et al., (2020), analyze three decades of the Journal of Teaching in International Business, from 1989 to 2019, using bibliometric methods. The study points out 4 thematic structures identified as international business education, international business curriculum, experiential learning and technology, and cross-cultural issues.

Visualization tools can help to teach and understand difficult concepts. They have been used in environmental education (see Wallis et al. (2012) and references therein). Venkatraman et al. (2019), explore visualization and experiential learning strategies in a higher education setting, and the effect of such an innovative teaching strategy to uplift mathematical skills.

However, only a few studies based on experiential learning applying visualisation techniques in teaching related to Business and Economics have been found in the literature. Bedawy (2017) presents an experiential learning model, using qualitative analysis that contributes to students' learning process and learning outcome. A recent one, Kulkarni (2019), analyses the perception of business school students with regard to their participation in entrepreneurial activities like the University of Manchester's annual business start-up competition. Five participants agreed to partake in the interviews and qualitative research was carried out to understand students' perceptions of an experiential learning. Visual techniques such as block and visual diagrams to explain the methodology for data collection or the hypothesis proposed in the conceptual model were used.

It is undeniable that the active-learning technique encourages students to become more involved with the course content through the application of theory to real-life situations. For that reason, we present in this paper not only an experiential learning in Business which provides a better understanding of statistics than did the students in a traditional class but a novelty use of visualization techniques in a qualitative study.

\section{Methodology}

This paper focuses on the analysis of the students' opinions on the development of an experiential activity based on the implementation of an electoral survey, which was carried out previously to the Spanish general elections in April 2019, with the purpose of estimating the vote in the municipality of Granada and other municipalities in its metropolitan area.

Data collected for this research were qualitative. The gathered information was subjected to a categorization process (Zhang et al., 2014). In order to unify and normalize the responses, similarity measures are used, according to criteria of lexical proximity and/or synonymy. With the aim to represent the underlying structure of the data, standard techniques in science mapping are applied, using graphical representations (Chen et al., 2002).

After a term clustering process (Zhang et al., 2014; Pinto et al., 2020), a co-word analysis is performed by providing a similarity matrix (Hu et al., 2013). The VosViewer software, developed to build and visualise bibliometric maps, is performed to analyze the relationships among terms and provide network maps (Van Eck et al., 2010; 2014), thus showing a new field of application of this software.

The information collected comes from an opinion survey of two open questions (What I liked the most, was... and What I liked the least, was...) conducted among 
the students of the subject Quantitative Techniques 2, which is taught in the second year of the Economics (GECO) and Business Administration and Management (GADE) degrees.

The undergraduate students were selected by non-random sampling. The sample consisted of 227 students, $50.2 \%$ female, with an average age of 20.49 years (SD 2.23).

\section{Results}

The opinions stated in the items What I liked the most, was... and What I liked the least, was... were associated with up to three terms, chosen in both cases from 15 options (Zhang et al., 2014). The list of terms and their frequency are listed in decreasing order in Table 1.

Table 1

Positive and Negative Terms

\begin{tabular}{|c|c|c|c|}
\hline Positive Aspects & Frequency & Negative Aspects & Frequency \\
\hline Electoral Survey & 203 & Data Collection & 38 \\
\hline Real Life and Current Affairs & 81 & Uninterested Respondents & 26 \\
\hline Apply Theory to Practice & 75 & Bad Attitude & 21 \\
\hline Learning Experience & 62 & Dealing with Strangers & 21 \\
\hline Political Reality & 58 & Rude People & 20 \\
\hline Conduct Surveys & 45 & Great Effort & 18 \\
\hline New and Useful & 42 & $\begin{array}{l}\text { The Activity Coincided with } \\
\text { other Tasks and Exams }\end{array}$ & 10 \\
\hline Comparison with Real Survey & 29 & Lack of Time & 8 \\
\hline Work Group & 24 & Less Participation in Work Group & 7 \\
\hline Meet People & 19 & Lack of Handling of Excel & 5 \\
\hline Motivation & 14 & Fill in Database & 4 \\
\hline Accuracy & 10 & I'm introverted/Shy & 5 \\
\hline $\begin{array}{l}\text { Better than an exam/Less } \\
\text { pressure }\end{array}$ & 9 & $\begin{array}{l}\text { There were some Errors in } \\
\text { Database }\end{array}$ & 2 \\
\hline Use Excel and Databases & 7 & Lack of Clarity in the Activity & 2 \\
\hline $\begin{array}{l}\text { Respondents' } \\
\text { attitude/Respondents' reaction }\end{array}$ & 6 & $\begin{array}{l}\text { Misunderstanding the Real } \\
\text { Applicability }\end{array}$ & 1 \\
\hline
\end{tabular}

Source: Author's illustration.

In order to picture the most significant expectations/opinions about this academic activity, the similarity matrix is obtained, containing the relationships between the responses (Hu et al., 2013).

Then, VOSViewer software is used to produce the density maps (Figure 1). By default, the colors range from blue-green to a yellow pattern: yellow refers to the highest element density and blue to the lowest element density. The size of the label increases with the weight of the term. 
Figure 1

Density View Showing the Strengths of the Most Frequently Used Terms

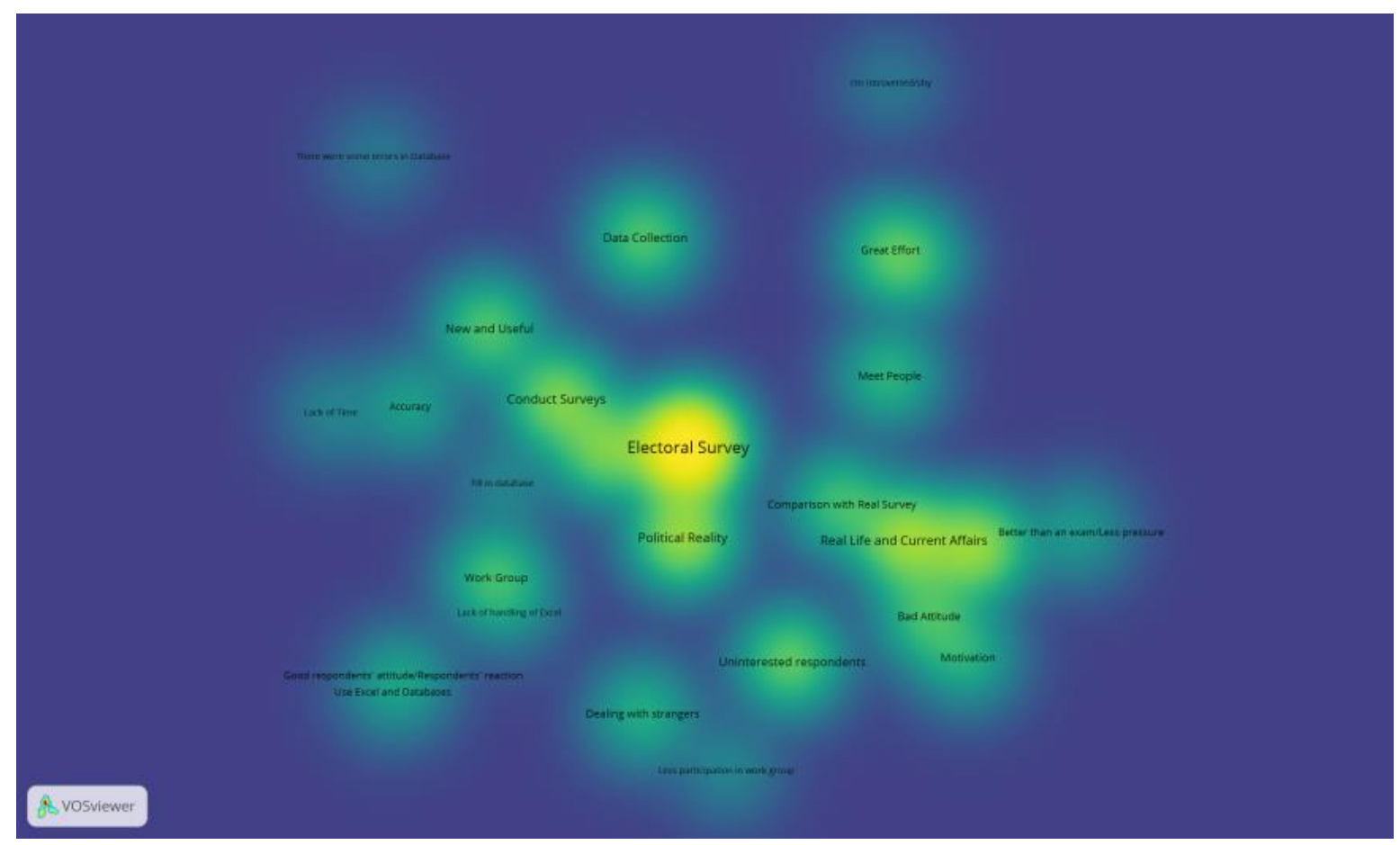

Source: Author's illustration

Finally, the network and cluster density view is generated using the VOS clustering technique, in which the element density of a point on a map is calculated separately for each cluster (Waltman et al., 2010). Then, a two-step process assigns each element to a cluster, considering a weighted average of the colors.

The network showing the relationships among the terms is shown below (Figure 2). In order of importance, the following four clusters can be distinguished:

- The first cluster (in red) consisted of eight terms: Applying theory to practice, Real life and Current affairs, Better than an exam/Less pressure, Comparison with real surveys, Motivation and Political reality, related to the positive terms and Bad attitude and Uninterested respondents appearing among the unfavorable opinions.

- The second cluster (in green) is composed of eight terms, on the one hand: Accuracy, Conduct surveys, Data collection, Learning Experience, New and Useful, and on the other hand, Lack of time, and There were some errors in the database.

- The third cluster (in blue) locates seven terms: Fill database, Good Respondents' attitude/respondents' reaction, Use Excel and Databases, Work Group associated with Dealing with strangers, Lack of handling of Excel, and Less participation in work.

- Finally, the fourth cluster (in yellow) is formed by four terms: Meet people, Great Effort, I'm introverted/shy, and The activity coincided with other tasks and exams. 
Figure 2

Network View

is VOSviewer

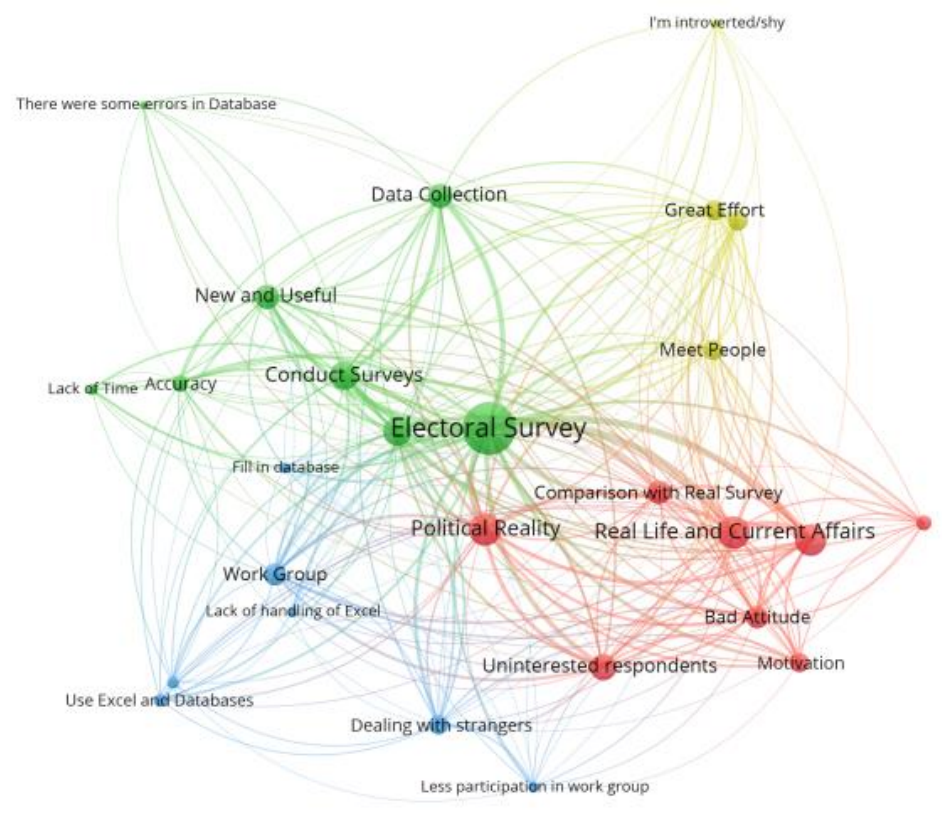

Source: Author's illustration

As it can be observed from Figure 2, each cluster is made up of a specific set of terms that are clearly located within a particular area of the map, showing the remarkable separation of the four thematic groups discovered.

\section{Discussion}

\section{Findings}

The experiential learning activity carried out has a multidisciplinary character (Slavich et al., 2012; Butler et al., 2019), connects theory and practice, leads to greater engagement (Haug et al., 2019), fosters interest, encourages critical thinking (Brickner et al., 2008), resulting in a deeper understanding of the subject (Selingo, 2016) and greater levels of satisfaction with the learning process. In line with these previous studies, after analyzing the information gathered, we can highlight the following aspects:

- The main assessment of the experiential learning carried out by an electoral survey reveals that students feel that it is a Current Affair, that it allows them to apply theory to practice and therefore it appears as novel and useful.

- As a learning experience, participants comment that they enjoyed conducting the Electoral Survey so that the activity allowed them to compare with real surveys or learn about the political reality. Besides, students involved valued the group work positively.

- To a lesser extent, they stated that they found it interesting to be able to handle Excel and large databases. The activity is considered a better option than an exam and it increased their motivation for the subject. They were surprised about the accuracy of their estimations and also by the strange reactions of some respondents, who seemed to lie or refused to participate. 
Among the aspects they more dislike, it can be highlighted:

- The fact that this type of activity helps to overcome shyness and to deal with strangers.

- The activity involves a great deal of effort due to the time needed to collect the data, fill in the database resting time to different assignments such as other tasks and exams.

- They complain about poor Excel skills and the lack of commitment of some members of the group

- Surprisingly, there is a general feeling of dissatisfaction with the attitude of some respondents, being rude or uninterested.

\section{Implications}

The outcome of this research shows that the experiential activity has helped students to improve their teamwork and communication skills, to deal with strangers, to understand different points of view, to develop an interest in other subjects, to overcome minor setbacks, and undoubtedly, to a better understanding of difficult concepts (Selingo, 2016; Kulkarni, 2019).

The lack of these skills can cause fatal consequences in the learning process. Therefore, the teacher must become a skillful facilitator, who knows how to choose the right didactics to promote effective learning (Espinar et al., 2020).

We also believe that it is essential to promote the incorporation of experiential activities in the classroom that favors engagement (Haug et al., 2019; AACSB, 2020), enabling the acquisition of knowledge, as well as the development of critical thinking skills. Furthermore, it encourages teamwork, allows them to develop their social skills and finally, increases global satisfaction with the learning process.

Academia should carry out evaluations of the teaching-learning processes in order to know the expectations, achievements, strengths and weaknesses (Bedawy, 2017; Cañabate et al., 2020). The analysis of these opinions is essential to adapt educational methodologies to the environment.

\section{Conclusions}

This paper shows the importance and usefulness of information visualization as a tool for analysis so that it enables to gain insights, extract value and communicate data (Sharma, 2020). This is applied to an experiential learning activity involving an Electoral Survey.

The categorization procedure proposed allows homogenizing and standardizing the responses. Then, the co-word analysis considered using VosViewer software let us to provide the network maps and show the interconnections among the opinions declared by students.

Results show the strengths of data visualisation enabling a better understanding of data (Chen, 2017) for qualitative studies. This methodology can be applied in further qualitative studies to analyze and represent the information collected, showing that data visualisation allows effective communication (Kirk, 2016; Kulkarni, 2019).

This study has been limited to the analysis of two qualitative items, which are part of a general opinion survey on the experiential activity carried out. This type of qualitative study could be extended by considering a larger number of questions to assess in detail opinions on specific aspects such as the development of teamwork, the development of critical thinking, expectations and assessments. 


\section{References}

1. Association to Advance Collegiate Schools of Business (AACSB) (2020), "Eligibility Procedures and Accreditation Standards for Business Accreditation", available at: http://www.aacsb.edu/accreditation/standards/business (20 May 2021)

2. Baden, D., Parkes, C. (2013), "Experiential learning: inspiring the leaders of tomorrow", The Journal of Management, Vol. 32 No. 3, pp. 295-308.

3. Bedawy, R. (2019), "Experiential Learning for Supporting Learning Effectiveness in Business Education: A Case Study from Egypt", International Journal of Business and Management, Vol. 12 No. 5, pp. 159-176.

4. Brickner, D. R., Etter E. R. (2008), "Strategies for promoting active learning in a principles of accounting course", Academy of Education Leadership Journal, Vol. 2 No.12, pp. 87-93.

5. Butler, M. G., Church, K. S., Spencer, A. W. (2019), "Do, reflect, think, apply: Experiential education in accounting", Journal of Accounting Education, Vol. 48, pp. 12-21.

6. Cañabate, D., Garcia-Romeu, M. L., Menció, A., Nogué, L., Planas, M., Solé-Pla, J. (2020), "Cross-Disciplinary Analysis of Cooperative Learning Dimensions Based on Higher Education Students' Perceptions", Sustainability, Vol. 12 No. 19, pp. 1-18.

7. Chen, C., McCain, K., White, H., Lin, X. (2002), "Mapping Scientometrics (1981-2001)", Proceedings of the American Society for Information Science and Technology, Vol. 1 No. 39, pp. 25-34.

8. Chen, H. M. (2017), "An overview of information visualization", Library Technology Reports, Vol. 3 No. 53, pp. 5-7.

9. Clark, J., White, G. (2010), "Experiential Learning: A Definitive Edge In The Job Market", American Journal of Business Education, Vol. 3 No. 2, pp. 115-118.

10.Coker, J. S., Porter, D. J. (2017), "Student motivations and perceptions across and within five forms of experiential learning", The Journal of General Education, Vol. 165 No. 2, pp. 138-156.

11.Espinar, E. A., Viguera, J. A. M. (2020), "El aprendizaje experiencial y su impacto en la educación actual", Revista Cubana de Educación Superior, Vol. 39 No. 3, pp. 1-14.

12.Haug, J. C., Berns Wright, L., Allen Huckabee, W. (2019), "Undergraduate business students' perceptions about engagement", Journal of Education for Business, Vol. 94 No. 2, pp. 81 91.

13.Hu, C. P., Hu, J. M., Deng, S. L., Liu, Y. (2013), "A co-word analysis of library and information science in China", Scientometrics, Vol. 97 No. 2, pp. 369-382.

14.Institute of Development Studies (2013), "Introduction to Data Visualisation", available at: www.researchtoaction.org/wp-content/uploads/2014/02/Introduction-to-DataVisualisation.pdf (20 May 2021)

15.Kirk, A. (2016), Data visualisation: A handbook for data driven design, Sage, London.

16.Kolb, A. Y., Kolb, D. A. (2017), "Experiential learning theory as a guide for experiential educators in higher education", Experiential Learning and Teaching in Higher Education, Vol. 1 No.1, pp. 7-44.

17.Kulkarni, P. P. (2019), "A qualitative analysis of the 'experiential learning' of business school students and graduates through their participation in The University of Manchester's annual business start-up competition", Entrepreneurship Education, Vol. 2, pp. 149-169.

18.McCarthy, M. (2016), "Experiential learning theory: From theory to practice", Journal of Business and Economics Research (JBER), Vol. 3 No. 14, pp. 91-100.

19.Pinto, M., Fernández-Pascual, R., Caballero-Mariscal, D., Sales, D. (2020), "Information literacy trends in higher education (2006-2019): visualizing the emerging field of mobile information literacy", Scientometrics, Vol. 2 No. 124, pp.1479-1510.

20.Selingo, J. J. (2016), There Is Life After College: What Parents and Students Should Know About Navigating School to Prepare for the Jobs of Tomorrow, HarperCollins, New York.

21.Sharma, A. M. (2020), "Data Visualization", in Kumari, S., Tripathy, K. K., Kumbhar, V. (Eds.), Data Science and Analytics, Emerald Publishing Limited, Bingley, pp. 1-22.

22.Slavich, G. M., Zimbardo, P. G. (2012), "Transformational Teaching: Theoretical Underpinnings, Basic Principles, and Core Methods", Educational Psychology Review, Vol. 4 No. 24, pp. $569-608$. 
23.Stopar, K., Bartol, T. (2019), "Digital competences, computer skills and information literacy in secondary education: mapping and visualization of trends and concepts", Scientometrics, Vol. 2 No. 118 , pp. 479-498.

24.Sureka, R., Donthu, N., Kumar, S. (2020), "Three Decades of the Journal of Teaching in International Business: A Bibliometric Overview", Journal of Teaching in International Business, Vol. 31 No. 3, pp. 259-285.

25.Van Eck, N. J., Waltman, L. (2010), "Software survey: VOSviewer, a computer program for bibliometric mapping", Scientometrics, Vol. 84 No. 2, pp. 523-538.

26.Van Eck, N. J., Waltman, L. (2014), "Visualizing bibliometric networks", in Ding, Y., Rousseau, R., Wolfram, D (Eds.), Measuring scholarly impact Cham, Springer, pp. 285-320.

27.Varian, H. (2009), "Hal Varian on how the Web challenges managers", available at: https://www.mckinsey.com/industries/technology-media-and-telecommunications/ourinsights/hal-varian-on-how-the-web-challenges-managers (20 May 2021)

28. Venkatraman, S., Overmars, A., Wahr, F. (2019), "Visualization and Experiential Learning of Mathematics for Data Analytics", Computation, Vol. 7 No. 3, pp. 1-13.

29.Vohra, N., Neerpal, R., Deepti, B. (2015), "Developing Leadership Skills among EMBA Students: Innovations in Design", The Journal for Decision Makers, Vol. 40 No. 1, pp. 15-27.

30.Wallis A., Graymore M., Matthews T., Byrne S. (2012), "A Visualisation Tool for Experiential Learning in Environmental Science", in Kim, M., Diong, C.H. (Eds.), Biology Education for Social and Sustainable Development, Sense Publishers, Rotterdam, pp. 73-86.

31.Waltman, L., Van Eck, N. J., Noyons, E. C. (2010), "A unified approach to mapping and clustering of bibliometric networks", Journal of Informetrics, Vol. 4 No. 4, pp. 629-635.

32.Zhang, Y., Porter, A. L., Hu, Z., Guo, Y., Newman, N. C. (2014), "“Term clumping" for technical intelligence: A case study on dye-sensitized solar cells", Technological Forecasting and Social Change, Vol. 85, pp. 26-39.

\section{About the authors}

Rosaura Fernández-Pascual is an Associate professor of Quantitative Methods at the Faculty of Economic and Business Sciences, University of Granada, Spain. Degree in Mathematics (1995), Pedagogic Aptitude Certificate, Expert in Epidemiology and Clinical Research (2003) and PhD in Mathematics (2003), University of Granada. She is an expert in Statistics and Quantitative Techniques applied to assessment in higher education. She has participated as a researcher of interdisciplinary R\&D projects on information literacy and mobile learning in Social Sciences. In addition, she has been the leading researcher of diverse projects on teaching innovation. The author can be contacted at rpascual@ugr.es

Ana Marin Jiménez is an assistant professor at the Department of Quantitative Methods in the Economy and Business of the University of Granada. Her expertise includes both the study of different statistical methods to compare binary diagnostic tests and Educational research, paying special attention to the statistical formation and collaborative learning supported by information technology. The author can be contacted at anamarin@ugr.es

María Pilar Fernández- Sánchez, gained MSc in Economics (1996) from the University of Santiago de Compostela (Spain). She started as an assistant professor in Business Statistics at the University of Granada in 1997 where received her PhD in Quantitative Methods Applied to Social Science (2002). Her research aim is connected to Risk Management or Insurance and has taken part in different projects related to these issues. Now she is focused on interdisciplinary projects in education, social issues, and applied statistics. Since November 2020 she is sub chief of the Department of Quantitative Methods in Economics at the Faculty of Economics (Granada, Spain). Author can be contacted at pilarfs@ugr.es 